\title{
Proposal for Elevation of the Family Acholeplasmataceae to Ordinal Rank: Acholeplasmatales
}

\author{
E. A. FREUNDT, ${ }^{1}$ R. F. WHITCOMB,${ }^{2 *}$ M. F. BARILE, ${ }^{3}$ S. RAZIN,${ }^{4}$ AND J. G. TULLY ${ }^{5} \dagger$ \\ Institute of Medical Microbiology, University of Aarhus, DK-8000, Aarhus C, Denmark ${ }^{1}$; Plant Protection Institute, \\ Agricultural Research Service, U. S. Department of Agriculture, Beltsville, Maryland 20705'; Mycoplasma Branch, \\ Bureau of Biologics, Food and Drug Administration, Bethesda, Maryland 202053 ; Department of Membrane and \\ Ultrastructure Research, Hebrew University-Hadassah Medical School, Jerusalem, Israel'; and Mycoplasma Section, \\ National Institute of Allergy and Infectious Diseases, Frederick Cancer Research Center, Frederick, Maryland 21701 ${ }^{5}$
}

\begin{abstract}
Species of the Acholeplasmataceae differ from species of the Mycoplasmataceae and Spiroplasmataceae in many respects, including lack of a nutritional requirement for sterol, ability of most species to synthesize saturated fatty acids and polyterpenes from acetate, and several other properties related to lipid metabolism and to the incorporation and location of lipids in the cell membrane. Acholeplasma species have also been found to differ from Mycoplasma species in possessing a nicotinamide adenine dinucleotide-dependent lactate dehydrogenase that is specifically activated by fructose 1,6-diphosphate and in containing superoxide dismutase, as well as glucose-6-phosphate and 6-phosphogluconate dehydrogenases. In addition, reduced nicotinamide adenine dinucleotide oxidase activity is located in the cell membrane of Acholeplasma species and is associated with the soluble cytoplasmic fraction of Mycoplasma and Spiroplasma species. Finally, significant differences exist between the nucleic acids of the Acholeplasmataceae and the Mycoplasmataceae. The genome molecular weight for Acholeplasma species is about $1.0 \times 10^{9}$, compared with about $5.0 \times 10^{8}$ for species of the Mycoplasmataceae. Moreover, a recent comparison of ribosomal ribonucleic acid oligonucleotide catalogs has demonstrated that Acholeplasma species are more closely related phylogenetically to two clostridial species than to the Mycoplasma and Spiroplasma species tested. Because the characteristics of species of the Acholeplasmataceae differ in major respects from those of other families of the Mollicutes, we propose elevation of the family Acholeplasmataceae to the rank of a new order, Acholeplasmatales. We provide a description of the proposed taxon, the second order of the class Mollicutes.
\end{abstract}

At present, three families are recognized in the order Mycoplasmatales Freundt 1955 (10), which is in the class Mollicutes Edward and Freundt 1967 (6); these are the Mycoplasmataceae Freundt 1955 (10), the Acholeplasmataceae Edward and Freundt 1970 (8), and the Spiroplasmataceae Skripal 1983 (48). Distinction among these three families depends primarily on differences in genome size, morphology, and nutritional requirements for sterol.

At its meeting in Freiburg, West Germany, in 1978 (14), the Subcommittee on the Taxonomy of Mollicutes discussed the possibility of elevation of the family Acholeplasmataceae to the rank of a separate order. The Subcommittee noted many profound differences that appeared to be suitable for separation of the Mycoplasmataceae and the Acholeplasmataceae at the ordinal level. Although all of the critical distinguishing tests had not been performed for each of the 71 species of Mycoplasmataceae, 4 species of Spiro-

\footnotetext{
* Corresponding author.

$\dagger$ For the International Committee on Systematic Bacteriology Subcommittee on the Taxonomy of Mollicutes. Remaining members of the Subcommittee are: J. M. Bové, Bordeaux, France; T. A. Chen, New Brunswick, N.J.; G. S. Cottew, Parkville, Victoria, Australia; H. Ernø, Aarhus, Denmark; K. Koshimizu, Tokyo, Japan; R. Leach, Norwich, United Kingdom; Ruth Lemcke, Compton, United Kingdom; H. Neimark, Brooklyn, N.Y.; D. TaylorRobinson, Harrow, United Kingdom; and P. Whittlestone, Cambridge, United Kingdom. Advisory members are: A. Rodwell, Parkville, Victoria, Australia; and J. Maniloff, Rochester, N.Y.
}

plasmataceae, or 10 species of Acholeplasmataceae, it was felt that most criteria had been adequately tested and that only very recently discovered criteria or species had not been extensively examined. Fewer but equally robust and adequately tested characteristics appeared to be available for separation of the Acholeplasmataceae from the third family of the Mycoplasmatales, the Spiroplasmataceae. After reviewing this evidence, a majority of the Subcommittee members felt that the unique properties which characterize the Acholeplasmataceae deserved recognition by elevation of the family to ordinal rank and decided to prepare a proposal to that effect. We summarize in this paper the properties that distinguish the Acholeplasmataceae from the Mycoplasmataceae and the Spiroplasmataceae and propose elevation of the family Acholeplasmataceae to ordinal rank.

The proposal by Edward and Freundt $(7,8)$ to establish a second genus and family (Acholeplasma and Acholeplasmataceae) in the order Mycoplasmatales was based primarily on the lack of a sterol requirement for growth of Acholeplasma species, a characteristic that appeared to be universally present in the species of the family Mycoplasmataceae $(37,46)$. More recently, dependence on sterol for growth has been shown to characterize members of the family Spiroplasmataceae $(47,53)$ and at least some members of the genus Anaeroplasma $(41,42)$, the latter which has not yet been assigned to a family.

The divergence in the sterol requirements of species of the Mollicutes is related to differences in the structure and composition of their cell membranes. Neither Mycoplasma 
nor Acholeplasma species are capable of synthesizing cholesterol. However, whereas cholesterol is an essential membrane component of Mycoplasma and other sterol-dependent species, this is not the case with Acholeplasma species (35).

Differentiation between sterol-requiring and sterol-nonrequiring members of the Mollicutes can be accomplished by direct $(5,37)$ or indirect methods. Indirect tests are based on differential susceptibility to amphotericin B (43), digitonin $(11,50)$, polyanethol-sulfonate $(11)$, lysolecithin $(22,51)$, and polyene antibiotics (12).

Certain other properties distinguish Acholeplasma species from Mycoplasma and Ureaplasma species. Whereas many Acholeplasma species are able to synthesize saturated fatty acids and polyterpenes from acetate, Mycoplasma species are not $(13,31,32,34,49)$. Another difference between Acholeplasma and Mycoplasma is the positional distribution of fatty acids in their membrane phosphatidylglycerol molecules. In two Acholeplasma species the saturated fatty acids are preferentially located at position 1 of glycerol, and the unsaturated fatty acids are located at position 2 , as is the rule elsewhere in nature $(23,44)$. However, in six Mycoplasma species, the positional distribution of the fatty acids is the reverse $(40,44,45)$. Finally, growing cells of some $M y c o-$ plasma species have been found to incorporate significant quantities of certain phospholipids (phosphatidylcholine and sphingomyelin), as well as free and esterified cholesterol. In contrast, Acholeplasma species fail to take up these phospholipids or esterified cholesterol and incorporate relatively small amounts of free cholesterol (36).

Additional physiological differences between Acholeplasma and Mycoplasma are of particular interest. For example, a nicotinamide adenine dinucleotide-dependent lactate dehydrogenase that is specifically activated by fructose 1,6-diphosphate is present in Acholeplasma but not in Mycoplasma species. This regulatory mechanism is uncommon and was previously known to occur only in the Lactobacillaceae, especially streptococci (26-28). The demonstration of serological relatedness between aldolases from Acholeplasma species and lactic acid bacteria (28) adds further weight to the phylogenetic implications of these observations. Moreover, some Acholeplasma species have been shown to differ from Mycoplasma species in producing a metalloenzyme, superoxide dismutase, that catalyzes the disproportionation of superoxide anions to $\mathrm{H}_{2} \mathrm{O}_{2}$ and $\mathrm{O}_{2}(16$, 18-20). In one study of multiple isoenzyme expression among Acholeplasma and Mycoplasma species, two enzymes in addition to superoxide dismutase, viz. glucose-6phosphate dehydrogenase and 6-phosphogluconate dehydrogenase, were found in Acholeplasma species but not in Mycoplasma species (29). These enzymatic activities may also prove to be important markers at the ordinal level. In addition to differences in the enzymatic capabilities of the two genera, there are also differences in the cellular site of certain key enzymatic activities. For example, reduced nicotinamide adenine dinucleotide oxidase and reduced nicotinamide adenine dinucleotide:ferricyanide oxidoreductase activities are associated with the cell membrane of Acholeplasma species, but with the soluble cytoplasmic fraction of Mycoplasma species $(30,31,33,54)$ and at least one Spiroplasma species $(15,24,25)$.

There are many significant differences in the molecular genetics of the Acholeplasmataceae and the Mycoplasmataceae. The demonstration of a genome molecular weight of $10^{9}$ for Acholeplasma species compared with $4.5 \times 10^{8}$ for Mycoplasma and Ureaplasma species (2) was considered by
Edward and Freundt (7) to provide important evidence in support of their proposal to assign the sterol-nonrequiring members of the Mollicutes to a separate genus and family.

Recent contributions in nucleic acid research, especially those concerning ribosomal ribonucleic acid (rRNA), have led to deeper insight into the phylogenetic relationships of the Mollicutes $(9,56)$. The special significance of these studies arises from the growing recognition that procaryotic rRNAs were highly conserved during evolution. Several observations indicate that this was also true of mycoplasmal rRNAs. For example, Reff et al. (39) examined the electrophoretic migration of rRNAs from bacteria, L-phase variants, acholeplasmas, and other members of the Mollicutes in nondenaturing gels and in formamide-containing gels and found that the migration patterns of mycoplasmal and acholeplasmal RNAs in nondenaturing gels were distinct not only from those of the bacteria examined, but also from each other, indicating some degree of phylogenetic divergence between the two groups. The significance of these studies was clarified considerably by studies involving digestion of $16 \mathrm{~S}$ rRNA by ribonuclease. In particular, the analyses of Woese et al. (56) and Fox et al. (9) of the base sequences of oligonucleotide catalogs from digested 16S rRNAs have initiated a new era in our understanding of the phylogenetic interrelationships in the Mollicutes. Of special interest is the finding of these workers that Mycoplasma gallisepticum, Mycoplasma capricolum, Spiroplasma citri, and Acholeplasma laidlawii possess base sequences that are otherwise almost exclusively confined to members of the BacillusLactobacillus-Streptococcus cluster. A closer analysis, based on a correction of the new raw data, suggested a specific relationship among $M$. gallisepticum, $M$. capricolum, and $S$. citri and a similar clustering of $A$. laidlawii with two species, Clostridium ramosum and Clostridium innocuum. According to this interpretation, Acholeplasma seemed to be phylogenetically more closely related to the two clostridial species than to species of Mycoplasma or Spiroplasma $(9,56)$. However, recent evidence based on studies of 5S RNA suggests a significant degree of relationship between Acholeplasma and Mycoplasma (55). The most recent proposal (21) for mollicute phylogeny suggests that the clusters consisting of the Acholeplasmataceae and the Mycoplasmataceae-Spiroplasmataceae group, although deeply divided, comprise a monophyletic branch of procaryote evolution. This branch, of course, corresponds to the class Mollicutes.

In summary, the genus Acholeplasma is distinguished by many nutritional, biochemical, physiological, and genetic characteristics that differ from those of the genus Mycoplas$m a$ and, to the extent that pertinent data are available, from those of the genus Ureaplasma, the second genus of the Mycoplasmataceae.

Fewer taxonomically pertinent characters distinguish the Acholeplasmataceae from the Spiroplasmataceae than from the Mycoplasmataceae. Although the Spiroplasma genome resembles the Acholeplasma genome in size, there are profound phenotypic differences between the taxa, which probably refiect equally profound differences in their molecular genetics. For example, the helical morphology and motility of members of the Spiroplasmataceae clearly distinguish this family from the Acholeplasmataceae. Members of the Spiroplasmataceae, like members of the Mycoplasmataceae, but in direct contrast to members of the Acholeplasmataceae, require sterols. Finally, as discussed above, evidence provided by Woese et al. (56) suggests a distant phylogenetic relationship between Acholeplasma and 
the cluster represented by $M$. gallisepticum, $M$. capricolum, and $S$. citri.

Although a common cytoplasmic antigen has been detected recently in five species of the Acholeplasmataceae (17), other observations document considerable heterogeneity in this family. For example, deoxyribonucleic acid-deoxyribonucleic acid hybridization tests between the type strains of eight Acholeplasma species (1) revealed, in most instances, less than $8 \%$ homology, although a cluster of four species showed 10 to $13 \%$ homology. The highest level of homology $(21 \%)$ was found between the type strains of $A$. laidlawii and Acholeplasma granularum. Moreover, the wide range of homology values (between 40 and 100\%) observed in comparisons of strains of $A$. laidlawii and Acholeplasma axanthum falls into the range observed in reactions among genera of the family Enterobacteriaceae (52). Deoxyribonucleic acid cleavage patterns after restriction endonuclease digestion (38) also reflect Acholeplasma heterogeneity. The heterogeneity in the Acholeplasma genome may be associated with the diversity of habitats (52). In contrast to acholeplasmas, most Mycoplasma species have narrow host ranges and, so far as is known, corresponding homogeneity in molecular genetic properties (38). It should be noted that our understanding of mollicute habitats is at present changing dramatically with the discovery of many new strains from plants and invertebrates $(3,4,52 a)$. These observations, which suggest that the concept of the Acholeplasmataceae appears to represent a heterogeneous group of organisms in a wide variety of habitats, are in accord with the decision to elevate the family to ordinal rank.

In consequence of these considerations, we formally propose elevation of the family Acholeplasmataceae to the rank of a separate order, Acholeplasmatales. The proposed new order becomes the second order of the class Mollicutes.

Description of Acholeplasmatales, order II of class Mollicutes Edward and Freundt 1967. Acholeplasmatales (A.cho.le.plas.ma.ta'les. M.L. neut. n. Acholeplasma type genus of the family Acholeplasmataceae; -ales ending to denote an order; M. L. fam. pl. n. Acholeplasmatales the Acholeplasma order).

Cells spherical and nonmotile, with a minimum diameter of ca. $300 \mathrm{~nm}$; filamentous, usually 2 to $5 \mu \mathrm{m}$ long. Reduced nicotinamide adenine dinucleotide oxidase activity located in the cell membrane. Generally more susceptible to osmotic shock at $37^{\circ} \mathrm{C}$ than members of the Mycoplasmatales. Colonies on solid media have a fried egg appearance and may reach 2 to $3 \mathrm{~mm}$ in diameter. Facultatively anaerobic; most strains grow readily in simple media. Sterols are not required for growth. Chemoorganotrophic, most species utilizing glucose and other sugars as the major energy sources. Carbohydrate transport occurs through an active carriermediated process different from the phosphoenolpyruvatedependent phosphotransferase system of some Mycoplasmatales species. Strains possess lactic dehydrogenases specifically activated by fructose 1,6-diphosphate. Many strains are capable of fatty acid biosynthesis from acetate. Arginine and urea are not hydrolyzed. Pigmented carotenoids, principally neurosporene, occur in some species. All species are resistant, or only slightly susceptible, to $1.5 \%$ digitonin. Saprophytes, parasites, or commensals of vertebrates, insects, or plants. None is known to be pathogenic. The guanine-plus-cytosine content of the deoxyribonucleic acid is approximately 27 to $36 \mathrm{~mol} \%$ (thermal melting and buoyant density methods). The genome molecular weight is approximately $1.0 \times 10^{9}$. Other characters are as for the class Mollicutes. The type family, Acholeplasmataceae Ed- ward and Freundt 1970 , is the only family and is monogeneric. The type genus is Acholeplasma Edward and Freundt 1970.

\section{LITERATURE CITED}

1. Aulakh, G. S., E. B. Stephens, D. L. Rose, J. G. Tully, and M. F. Barile. 1983. Nucleic acid relationships among Acholeplasma species. J. Bacteriol. 153:1338-1341.

2. Bak, A. L., F. T. Black, C. Christiansen, and E. A. Freundt. 1969. Genome size of mycoplasmal DNA. Nature (London) 224:1209-1210.

3. Clark, T. B. 1982. Spiroplasmas: diversity of arthropod reservoirs and host-parasite relationships. Science 217:57-59.

4. Eden-Green, S. J., and J. G. Tully. 1979. Isolation of Acholeplasma spp. from coconut palms affected by lethal yellowing disease in Jamaica. Curr. Microbiol. 2:311-316.

5. Edward, D. G. ff. 1971. Determination of sterol requirement for Mycoplasmatales. J. Gen. Microbiol. 69:205-210.

6. Edward, D. G. ff. and E. A. Freundt. 1967. Proposal for Mollicutes as name of the class established for the order Mycoplasmatales. Int. J. Syst. Bacteriol. 17:267-268.

7. Edward, D. G. ff., and E. A. Freundt. 1969. Proposal for classifying organisms related to Mycoplasma laidlawii in a family Sapromycetaceae, genus Sapromyces, within the Mycoplasmatales. J. Gen. Microbiol. 57:391-395.

8. Edward, D. G. ff., and E. A. Freundt. 1970. Amended nomenclature for strains related to Mycoplasma laidlawii. J. Gen. Microbiol. 62:1-2.

9. Fox, G. E., E. Stackebrandt, R. B. Hespell, J. Gibson, J. Maniloff, T. A. Dyer, R. S. Wolfe, W. E. Balch, R. S. Tanner, L. J. Magrum, L. B. Zablen, R. Blakemore, R. Gupta, L. Bonen, B. J. Lewis, D. A. Stahl, K. R. Luehrsen, K. N. Chen, and C. R. Woese. 1980. The phylogeny of prokaryotes. Science 209:457463.

10. Freundt, E. A. 1955. The classification of the pleuropneumonia group of organisms (Borrelomycetales). Int. Bull. Bacteriol. Nomencl. Taxon. 5:67-78.

11. Freundt, E. A., B. E. Andrews, H. Ernø, M. Kunze, and F. T. Black. 1973. The sensitivity of Mycoplasmatales to sodiumpolyanethol-sulfonate and digitonin. Zentralbl. Bakteriol. Parasitenkd. Infektionskr. Hyg. Abt. 1 Orig. Reihe A 225:104-112.

12. Grabowski, M. W., S. Rottem, and M. F. Barile. 1976. Cholesterol requirement of mycoplasmas as determined by a microtiter test using polyene antibiotics. J. Clin. Microbiol. 3:110-112.

13. Herring, P. K., and J. D. Pollack. 1974. Utilization of $\left[1-{ }^{14} \mathrm{C}\right]$ acetate in the synthesis of lipids by acholeplasmas. Int. J. Syst. Bacteriol. 24:73-78.

14. International Committee on Systematic Bacteriology Subcommittee on the Taxonomy of Mollicutes. 1982. Minutes of the meeting, 27 and 30 August and 5 September, 1978. Int. J. Syst. Bacteriol. 32:261-264.

15. Kahane, I., S. Greenstein, and S. Razin. 1977. Carbohydrate content and enzymatic activities in the membrane of Spiroplasma citri. J. Gen. Microbiol. 101:173-176.

16. Kirby, T., J. Blum, I Kahane, and L. Fridovich. 1980. Distinguishing between Mn-containing and Fe-containing superoxide dismutases in crude extracts of cells. Arch. Biochem. Biophys. 201:551-555.

17. Lee, G. Y., and G. E. Kenny. 1983. Common cytoplasmic antigen in five Acholeplasma species. Int. J. Syst. Bacteriol. 33:356-363.

18. Lee, G. Y., and G. E. Kenny. 1984. Immunologic heterogeneity of superoxide dismutases in the Acholeplasmataceae. Int. J. Syst. Bacteriol. 34:74-76.

19. Lynch, R. E., and B. C. Cole. 1980. Mycoplasma pneumoniae: a prokaryote which consumes oxygen and generates superoxide but which lacks superoxide dismutase. Biochem. Biophys. Res. Commun. 96:98-105.

20. Lynch, R. E., and B. C. Cole. 1980. Mycoplasma pneumoniae: a pathogen which manufactures superoxide but lacks superoxide dismutase, p. 49-56. In W. H. Bannister and J. V. Bannister (ed.), Biological and clinical aspects of superoxide dismutase. 
Elsevier/North-Holland Publishing Co., Amsterdam.

21. Maniloff, J. 1983. Evolution of wall-less prokaryotes. Annu. Rev. Microbiol. 37:477-499.

22. Mårdh, P.-A., and D. Taylor-Robinson. 1973. The differential effect of lysolecithin on mycoplasmas and acholeplasmas. Med. Microbiol. Immunol. 158:219-226.

23. McElhaney, R. N., and M. E. Tourtellotte. 1970. The relationship between fatty acid structure and the positional distribution of esterified fatty acids in phosphatidyl glycerol from Mycoplasma laidlawii B. Biochim. Biophys. Acta 202:120-128.

24. Mudd, J. B., M. Ittig, B. Roy, J. Latrille, and J. M. Bové. 1977. Composition and enzyme activities of Spiroplasma citri membranes. J. Bacteriol. 129:1250-1256.

25. Mudd, J. B., I.-M. Lee, H.-Y. Liu, and E. C. Calavan. 1979. Comparison of membrane composition of Spiroplasma citri and the corn stunt Spiroplasma. J. Bacteriol. 137:1056-1058.

26. Neimark, H. 1973. Molecular evolutionary studies of mycoplasmas and acholeplasmas. Ann. N. Y. Acad. Sci. 225:14-21.

27. Neimark, H., and R. M. Lemcke. 1972. Occurrence and properties of lactic dehydrogenases of fermentative mycoplasmas. J. Bacteriol. 111:633-650.

28. Neimark, H., and J. London. 1982. Origins of the mycoplasmas: sterol-nonrequiring mycoplasmas evolved from streptococci. J. Bacteriol. 150:1259-1265.

29. O'Brien, S. J., J. M. Simonson, M. W. Grabowski, and M. F. Barile. 1981. Analysis of multiple isoenzyme expression among twenty-two species of Mycoplasma and Acholeplasma. J. Bacteriol. 146:222-232.

30. Pollack, J. D. 1975. Localization of reduced nicotinamide adenine dinucleotide oxidase activity in Acholeplasma and $\mathrm{Myco}$ plasma species. Int. J. Syst. Bacteriol. 25:108-113.

31. Pollack, J. D. 1978. Differentiation of Mycoplasma and Acholeplasma. Int. J. Syst. Bacteriol. 28:425-426.

32. Pollack, J. D., K. D. Beaman, and J. A. Robertson. 1984 Synthesis of lipids from acetate is not characteristic of Acholeplasma or Ureaplasma species. Int. J. Syst. Bacteriol. 34:124126.

33. Pollack, J. D., S. Razin, and R. C. Cleverdon. 1965. Localization of enzymes in Mycoplasma. J. Bacteriol. 90:617-622.

34. Pollack, J. D., and M. E. Tourtellotte. 1967. Synthesis of saturated long chain fatty acids from sodium acetate-1- $\mathrm{C}^{14}$ by Mycoplasma. J. Bacteriol. 93:636-641.

35. Razin, S. 1982. Sterols in mycoplasma membranes. Curr. Top. Membr. Transp. 17:183-205.

36. Razin, S., S. Kutner, H. Efrati, and S. Rottem. 1980. Phospholipid and cholesterol uptake by mycoplasma cells and membranes. Biochim. Biophys. Acta 598:628-640.

37. Razin, S., and J. G. Tully. 1970. Cholesterol requirement of mycoplasmas. J. Bacteriol. 102:306-310.

38. Razin, S., J. G. Tully, D. L. Rose, and M. F. Barile. 1983. DNA cleavage patterns as indicators of genotypic heterogeneity ámong strains of Acholeplasma and Mycoplasma species. J. Gen. Microbiol. 129:1935-1944.

39. Reff, M. E., E. J. Stanbridge, and E. L. Schneider. 1977. Phylogenetic relationships between mycoplasmas and other procaryotes based upon the electrophoretic behavior of their ribosomal ribonucleic acids. Int. J. Syst. Bacteriol. 27:185-193.

40. Rigaud, J.-L., and G. Leblanc. 1980. Effect of membrane cholesterol on action of phospholipase $\mathrm{A}_{2}$ in Mycoplasma mycoides var. capri. Eur. J. Biochem. 110:77-84

41. Robinson, I. M., and M. J. Allison. 1975. Transfer of Acholeplasma bactoclasticum Robinson and Hungate to the genus Anaeroplasma (Anaeroplasma bactoclasticum [Robinson and Hungate] comb. nov.): emended description of the species. Int. J. Syst. Bacteriol. 25:182-186.

42. Robinson, I. M., M. J. Allison, and P. A. Hartman. 1975. Anaeroplasma abactoclasticum gen. nov., sp. nov.: an obligately anaerobic mycoplasma from the rumen. Int. J. Syst. Bacteriol. 25:173-181.

43. Rottem, S. 1972. Differentiation of sterol-requiring from sterolnonrequiring mycoplasmas by amphotericin B. Appl. Microbiol. 23:659-660.

44. Rottem, S., and O. Markowitz. 1979. Unusual positional distribution of fatty acids in phosphatidylglycerol of sterol-requiring mycoplasmas. FEBS Lett. 107:379-382.

45. Rottem, S., and O. Markowitz. 1979. Membrane lipids of Mycoplasma gallisepticum: a disaturated phosphatidylcholine and phosphatidylglycerol with an unusual positional distribution of fatty acids. Biochemistry 18:2930-2935.

46. Rottem, S., E. A. Pfendt, and L. Hayflick. 1971. Sterol requirements of T-strain mycoplasmas. J. Bacteriol. 105:323-330.

47. Saglio, P., M. Lhospital, D. Laflèche, G. Dupont, J. M. Bové, J. G. Tully, and E. A. Freundt. 1973. Spiroplasma citri gen. and sp. n.: a mycoplasma-like organism associated with "stubborn" disease of citrus. Int. J. Syst. Bacteriol. 23:191-204.

48. Skripal, I. G. 1983. Revival of the name Spiroplasmataceae fam. nov., nom. rev., omitted from the 1980 Approved Lists of Bacterial Names. Int. J. Syst. Bacteriol. 33:408.

49. Smith, P. F. 1979. The composition of membrane lipids and lipopolysaccharides, p. 231-257. In M. F. Barile and S. Razin (ed.), The mycoplasmas, vol. 1. Academic Press, Inc., New York.

50. Smith, P. F., and G. R. Rothblat. 1960. Incorporation of cholesterol by pleuropneumonia-like organisms. J. Bacteriol. 80:842-850.

51. Soltesz, L. V., and P.-A. Mårdh. 1977. The lytic effect of lysolecithin on acholeplasmas and mycoplasmas. Acta Pathol. Microbiol. Scand. Sect. B 85:255-261.

52. Stephens, E. B., G. S. Aulakh, D. L. Rose, J. G. Tully, and M. F. Barile. 1983. Intraspecies genetic relatedness among strains of Acholeplasma laidlawii and Acholeplasma axanthum by nucleic acid hybridization. J. Gen. Microbiol. 129:1929-1934.

52a.Tully, J. G. 1983. Reflections on recovery of some fastidious Mollicutes with implications of the changing host patterns of these organisms. Yale J. Biol. Med. 56:799-813.

53. Tully, J. G., R. F. Whitcomb, D. L. Rose, and J. M. Bové. 1982. Spiroplasma mirum, a new species from the rabbit tick (Haemaphysalis leporispalustris). Int. J. Syst. Bacteriol. 32:92-100.

54. Vinther, O., and E. A. Freundt. 1977. Ultrastructural localization of tellurite reduction in Acholeplasma species. Acta Pathol. Microbiol. Scand. Sect. B 85:184-188.

55. Walker, R. T., E. T. J. Chelton, M. W. Kilpatrick, M. J. Rogers, and J. Simmons. 1982. The nucleotide sequence of the 5S rRNA from Spiroplasma species BC-3 and Mycoplasma mycoides subsp. capri PG-3. Nucleic Acids Res. 10:6363-6367.

56. Woese, C. R., J. Maniloff, and L. B. Zablen. 1980. Phylogenetic analysis of the mycoplasmas. Proc. Natl. Acad. Sci. U.S.A. 77:494-498. 